\title{
Giant fibroepithelial polyp of the ureter
}

\author{
Mayank Gupta, ${ }^{1}$ Sanjeet Roy, ${ }^{1}$ Cornerstone Wann, ${ }^{2}$ Anu Eapen ${ }^{3}$
}

${ }^{1}$ Department of General Pathology, Christian Medical College, Vellore, India ${ }^{2}$ Department of Urology, Christian Medical College, Vellore, India ${ }^{3}$ Department of Radiodiagnosis and Imaging, Christian Medical College, Vellore, India

Correspondence to Dr Mayank Gupta, gupta.mayank103@gmail.com

Accepted 22 March 2017

\section{CrossMark}

To cite: Gupta M, Roy S, Wann C, et al. BMJ Case Rep Published Online First: [please include Day Month Year]. doi:10.1136/bcr-2016 218999

\begin{abstract}
SUMMARY
Giant fibroepithelial polyp is a rare cause of ureteric/ ureteropelvic junction (UPJ) obstruction. We report a rare case of giant fibroepithelial polyp in a 32-year-old woman involving the whole length of the ureter, reaching up to the UPJ which was clinically and radiologically considered to be urothelial carcinoma. Frozen section showed a polypoid lesion lined by urothelium with no evidence of dysplasia or malignancy. Subsequently, nephroureterectomy was done as there was marked renal hydronephrosis and it was impossible to separate the polyp from the wall of the ureter. Histopathological examination and immunohistochemistry confirmed the diagnosis of giant fibroepithelial polyp, ruling out malignancy.
\end{abstract}

\section{BACKGROUND}

Neoplasms primarily involving the ureter are very rare and account for less than $1 \%$ of genitourinary neoplasms. Very few of these neoplasms are benign and one them is a fibroepithelial polyp which is of mesodermal origin and can mimic urothelial carcinoma clinically and radiologically. ${ }^{1}$ These ureteric polyps usually have male preponderance, occur in the second to fourth decades and particularly involve the proximal ureter and renal pelvis. ${ }^{1}$ ${ }^{2}$ They commonly present with flank pain and/or haematuria. ${ }^{2}$ Some of these polyps are very large in size and may involve the whole length of the ureter mimicking urothelial carcinoma clinically and radiologically. Hence, intraoperative cystoscopy and frozen section are necessary to rule out malignancy. We report a similar case of giant ureteral fibroepithelial polyp in a 32-year-old woman.

\section{CASE PRESENTATION}

A 32-year-old married woman, a housewife presented with complaints of painless haematuria since 1 year without any associated lower urinary tract symptoms. There was no history of fever, flank pain, vomiting, urinary tract infection or history of intake of any drugs. She had completed her family (two children; last child birth was 4 years back) and she was a non-smoker. Urine microscopy showed numerous red blood cells (RBCs) and occasional pus cells but was negative for malignant cells. Urine culture did not grow any bacteria. Haemogram showed mildly decreased haemoglobin. Liver function test, fasting blood glucose, postprandial blood glucose, glycosylated hemoglobin, serum creatinine and blood urea nitrogen levels were within normal range.

CT abdomen shows a right ureteric mass lesion with renal hydronephrosis and no involvement of urinary bladder (figure $1 \mathrm{~A}$ and $\mathrm{B}$ ). In view of the size of the lesion, radiological diagnosis of urothelial carcinoma was considered. Left kidney and other organs were unremarkable. There was no lymphadenopathy. Chest X-ray, CT thorax and CT of pelvic region were unremarkable. The diagnosis and subsequent treatment were discussed with the patient and her husband. They were informed that intraoperative cystoscopy and frozen section shall be done to confirm the diagnosis. They were explained that if the frozen report is suggestive of carcinoma, nephroureterectomy will be performed (written informed consent was obtained).

Intraoperative cystoscopy showed a small $1 \mathrm{~cm}$ tumour protruding into the bladder from the right ureteric orifice (figure 1C). Rest of the bladder mucosa was normal. Subsequently, a small bit of tumour projecting from the ureteric orifice was submitted for frozen section. Microscopically, a polypoid lesion lined by mature urothelium was evident. The suburothelial region showed oedema, congested vessels and scattered chronic inflammatory cells. There was no evidence of dysplasia or malignancy. Frozen report was discussed with the patient's husband. Considering the size of the lesion reaching up to the pelvi-ureteric junction and marked hydronephrosis with renal parenchymal thinning, right nephroureterectomy was done (written informed consent obtained again from patient's husband after frozen report). Her postoperative period was uneventful.

Gross examination revealed ureter, measuring $20 \mathrm{~cm}$ in length and dilated to a diameter of $3-4 \mathrm{~cm}$ with a tumour involving the entire length of the ureter and reaching upto the renal pelvicalyceal system. The right kidney showed marked parenchymal thinning and marked hydronephrosis (figure 1D, figure 2). Histopathological examination revealed a polyp displaying loose fibrovascular stroma containing small and large thick wall blood vessels and scattered chronic inflammatory cells covered by mature urothelium (figure 3). Numerous von Brunn's nests were seen in the suburothelial stroma displaying minimal to mild nuclear atypia; however, mitotic figures were not evident (figure 4). Overlying urothelium and von Brunn's nests immunonegative for p53 (figure 5a) and CK20 (figure 5b) along with Ki-67 (MIB-1) labelling index $\sim 1 \%$ confirmed the benign nature of the lesion. Thus, a diagnosis of giant benign fibroepithelial polyp was made.

Follow-up of the patient (regular clinical examination, urine examination and radiological investigation) for 1 year has been uneventful. Presently, she is on regular follow-up. 

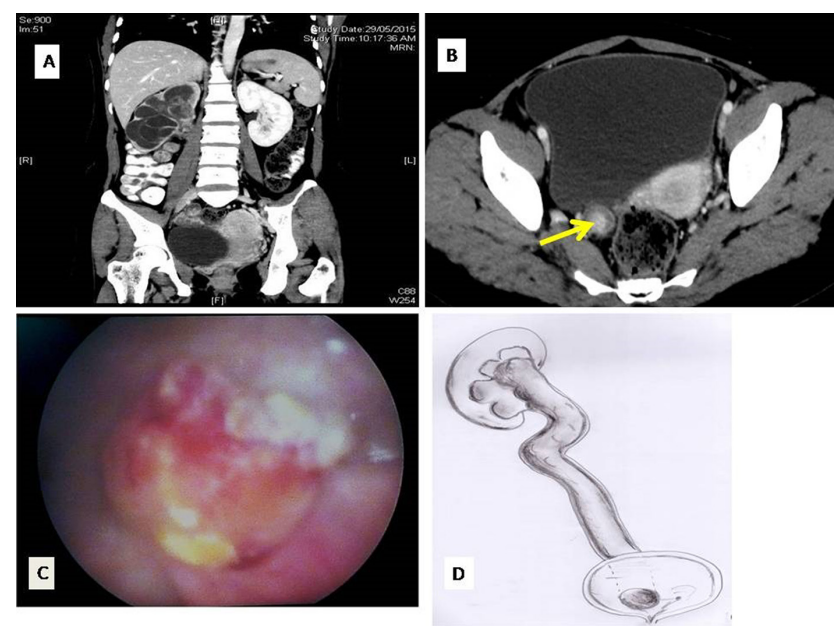

Figure 1 (A) CT abdomen shows a large heterogeneous multicystic lesion with solid components filling the right ureter, arising from its distal part and protruding into dilated right pelvicalyceal system. Marked dilatation and tortuosity of the ureter are evident. The right kidney appears hydronephrotic with marked parenchymal thinning. (B) CT of the pelvic region (axial image) shows an enhancing lesion (arrow) filling the right lower ureter upto the vesicoureteric junction with no extension into urinary bladder. (C) Cystoscopic image showing a tumour protruding through the right ureteric orifice. (D) Illustration depicting the polypoid growth involving the whole length of the ureter.

\section{DISCUSSION}

Fibroepithelial polyps are rare benign mesenchymal tumours involving the ureter and renal pelvis. ${ }^{34}$ Grossly, they are seen as finger-like projections originating from the submucosa of the ureter attached to a common base. ${ }^{15}$

Number of cases of fibroepithelial polyps involving the ureter have been reported ${ }^{6-8}$; however, very few cases of giant fibroepithelial polyps have been previously reported. ${ }^{19-12}$ Momenzadeh et al reported a case of giant fibroepithelial polyp in a 44-year-old woman who presented with dysuria, lower abdominal pain and microscopic haematuria. Cystoscopy showed a pedunculated polypoid tumour near the right uretero-vesical orifice, which was resected completely. ${ }^{1}$ Coloma del Peso et al reported a case of giant
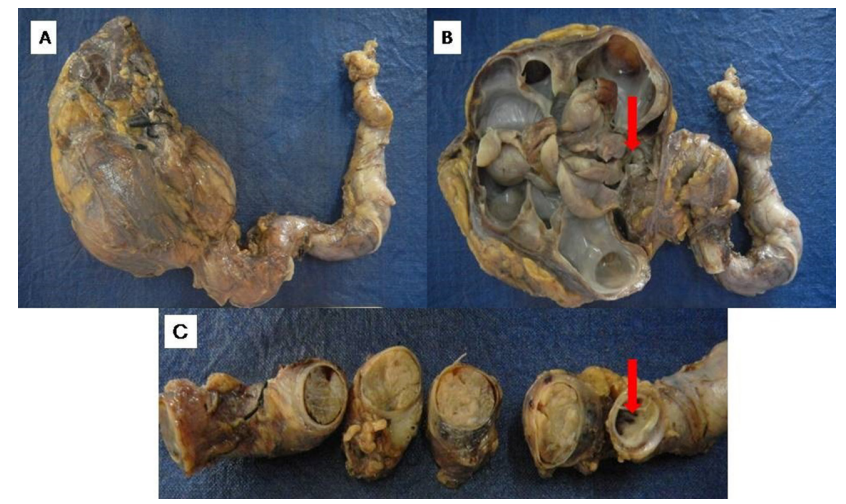

Figure 2 (A) Macroscopic image of the right kidney and dilated ureter (immediately after fixation, both kidney and ureter are unsectioned). (B) Macroscopic image displaying markedly dilated renal pelvis with marked thinning of renal parenchyma. Dilated ureter with the polypoid growth reaching up to the pelvi-ureteric junction is also evident (red arrow). (C) Macroscopic image of the polypoid growth involving the ureteric lumen and obliterating it. Cystic change is evident (red arrow).
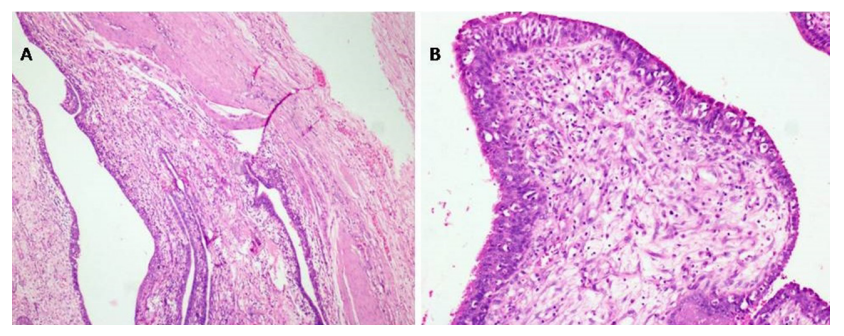

Figure 3 Microscopic image of the polyp arising from the wall of the ureter. There is no dysplasia involving the overlying urothelium; ((A): 4x magnification), ((B): 10x magnification); H\&E stain.

fibroepithelial polyp in a 42-year-old woman who presented with haematuria and right-sided colicky pain in lower back. ${ }^{9}$ Liu also reported a case of 42-year-old woman with an incidentally detected bladder mass. ${ }^{10}$ Imaging and cystoscopy in both the cases showed a pedunculated polypoid lesion protruding into the bladder, reaching up to the middle third of the ureter. In both of these cases, the polyp was excised with the help of laser. ${ }^{9}{ }^{10}$ Kaba et al reported a case of 14-year-old boy who presented with haematuria. Imaging and cystoscopy showed a mass originating at the middle third of the ureter and protruding into the bladder. The polyp was excised and ureteral end-to-end anastomosis was done. ${ }^{11}$ As far as our case is concerned, the polyp involved the whole length of the ureter, reaching up to the renal pelvis and it was impossible to separate the polyp from the ureteric wall. Moreover, the kidney showed marked hydronephrosis with loss of corticomedullary differentiation. Hence, nephroureterectomy was done in spite of the benign nature of the lesion. Previously one case of giant fibroepithelial polyp of the ureter has been reported wherein nephroureterectomy was done. ${ }^{12}$

Irrespective of the frozen section report, nephroureterectomy had to be done in our case. However, intraoperative frozen section was done to confirm/exclude the clinical and radiological diagnosis of urothelial carcinoma as our patient was a young woman with no predisposing factors for urothelial carcinoma. Preoperative functional scan was not done in our case as the clinical and radiological diagnosis was urothelial carcinoma.

The aetiology of these fibroepithelial polyps is unclear; however, it is speculated that chronic persistent irritation due to renal stones, infection, obstruction, trauma and developmental

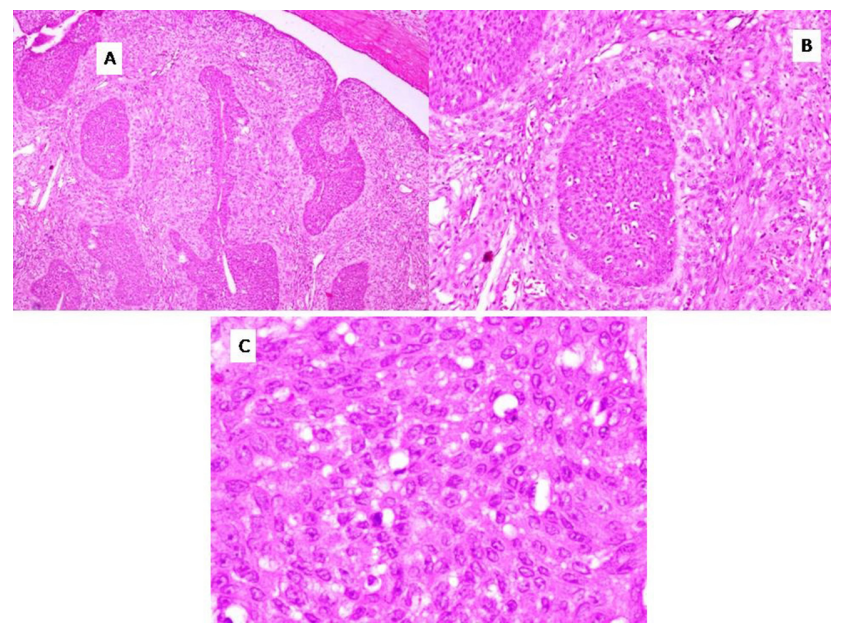

Figure 4 H\&E stain showing clusters of benign urothelial cells in the subepithelial region representing von Brunn's nests; ((A): $4 \mathrm{x}$ magnification), ((B): 10x magnification) and ((C): 20x magnification). 


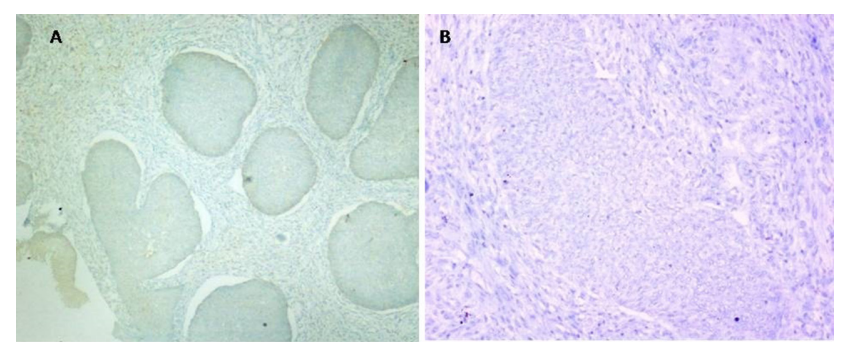

Figure 5 Clusters of benign urothelial cells in the subepithelial region are negative for $\mathrm{p} 53$; ((A): 10x magnification) and CK20 ((B): 20x magnification); immunohistochemistry.

defects may be the causative factors. ${ }^{11}$ As far as our case is concerned, there were no definite aetiological factors.

The overlying urothelium did not show any degree of dysplasia in our case. Clusters of urothelial cells were seen in the lamina propria; however, they did not exhibit mitotic figures and significant nuclear atypia, hence these clusters were considered as von Brunn's nests. ${ }^{13}$ Moreover, these von Brunn's nests did not express p53 and CK20 and MIB-1 labelling index was $\sim 1 \%$, confirming the benign nature of the lesion, ruling out nested variant of urothelial carcinoma. ${ }^{14}$

The risk of developing malignancy (urothelial carcinoma) in a benign ureteral fibroepithelial polyp is very less with only a few cases reported in literature. ${ }^{15-17}$

In conclusion, we present a rare case of giant ureteral fibroepithelial polyp, clinically and radiologically mimicking urothelial carcinoma, highlighting an atypical presentation of a rare benign entity.

\section{Learning points}

- Fibroepithelial polyps are rare benign mesenchymal tumours involving the ureter and renal pelvis.

- It is speculated that chronic persistent irritation due to renal stones, infection, obstruction, trauma and developmental defects may be responsible for the development of fibroepithelial polyps in the ureter.

- Giant fibroepithelial ureteral polyp mimics urothelial carcinoma clinically and radiologically, hence frozen section is necessary to confirm its diagnosis and rule out malignancy, particularly in young patients.

- The risk of developing urothelial carcinoma in a benign ureteral fibroepithelial polyp is very less.
Contributors MG and SR were involved in defining intellectual content, literature search, manuscript preparation, editing and manuscript review. CW provided the clinical details and was involved in manuscript editing and manuscript review. AE provided the radiological details and was involved in manuscript editing and manuscript review.

Competing interests None declared.

\section{Patient consent Obtained.}

Provenance and peer review Not commissioned; externally peer reviewed.

(C) BMJ Publishing Group Ltd (unless otherwise stated in the text of the article) 2017. All rights reserved. No commercial use is permitted unless otherwise expressly granted.

\section{REFERENCES}

1. Momenzadeh A, Sarrafzadeh F, Nourbala MH, et al. Giant ureteral fibroepithelial polyp presenting as a bladder mass resected ureteroscopically: a case report. Nephrourol Mon 2013;5:706-8.

2. Williams TR, Wagner BJ, Corse WR, et al. Fibroepithelial polyps of the urinary tract. Abdom Imaging 2002;27:217-21.

3. Goldman SM, Bohlman ME, Gatewood OM. Neoplasms of the renal collecting system. Semin Roentgenol 1987;22:284-91.

4. Wolgel CD, Parris AC, Mitty HA, et al. Fibroepithelial polyp of renal pelvis. Urology 1982; 19:436-9.

5. Yagi $S$, Kawano Y, Gotanda T, et al. Endoscopic treatment of a long fibroepithelial ureteral polyp. Int J Urol 2001;8:467-9.

6. Shive ML, Baskin LS, Harris CR, et al. Ureteral fibroepithelial polyp causing urinary obstruction. J Radiol Case Rep 2012;6:23-8.

7. Turunc T, Kuzgunbay B, Canpolat T. Ureteral fibroepithelial polyps with calculi: a case series. J Med Case Rep 2008:2:280.

8. Tekdogan UY, Canakli F, Aslan Y, et al. Bilateral ureteral fibroepithelial polyps and review of the literature. Int J Urol 2005;12:98-100.

9. Coloma del Peso A, Bocardo Fajardo G, Teba del Pino F, et al. Endoscopic treatment of a giant fibroepithelial polyp of the ureter. Arch Esp Urol 2010:63:305-8

10. Liu C, Liu XJ, Liu D, et al. A giant ureteral polyp mimicking as a bladder mass resected ureteroscopically by diode laser: a case report and literature review. Int J Clin Exp Pathol 2015;8:14580-3.

11. Kaba M, Kaba S, Kaya TY, et al. A giant pedunculated urothelial polyp mimicking bladder mass in a child: a rare case. Case Rep Pediatr 2014:2014:1-3

12. Rigabert Montiel M, Martínez Barba E, López Cubillana P, et al. Giant fibroepithelial polyp of the ureter. Arch Esp Urol 2000;53:940-3.

13. Young RH. Non-neoplastic disorders of the urinary bladder. In: Bostwick DG, Cheng L, eds. Urologic surgical pathology. 2nd ed. Maryland Heights, MO: Mosby Elsevier;2008:219-20.

14. Cheng L, Lopez-Beltran A, MacLennan GT, et al; Neoplasms of the urinary bladder. In: Bostwick DG, Cheng L, eds. Urologic surgical pathology. 2nd ed. Maryland Heights, MO: Mosby Elsevier, 2008:289.

15. Zervas A, Rassidakis G, Nakopoulou L, et al. Transitional cell carcinoma arising from a fibroepithelial ureteral polyp in a patient with duplicated upper urinary tract. J Urol 1997; 157:2252-3.

16. Min K, Jung SJ, Chung Jl, et al. Urothelial carcinoma arising from a large ureteral polyp. Korean J Urol 2012;53:807-9.

17. Davides KC, King LM. Fibrous polyps of the ureter. J Urol 1976;115:651-3.

Copyright 2017 BMJ Publishing Group. All rights reserved. For permission to reuse any of this content visit

http://group.bmj.com/group/rights-licensing/permissions.

BMJ Case Report Fellows may re-use this article for personal use and teaching without any further permission.

Become a Fellow of BMJ Case Reports today and you can:

- Submit as many cases as you like

- Enjoy fast sympathetic peer review and rapid publication of accepted articles

- Access all the published articles

- Re-use any of the published material for personal use and teaching without further permission

For information on Institutional Fellowships contact consortiasales@bmjgroup.com

Visit casereports.bmj.com for more articles like this and to become a Fellow 